\title{
The Assessment of Accredited Faculties Performance at Assiut University by Using Balanced Scorecard (BSC)
}

\author{
Bahaaaldeen Arabi Mohamad Mohamad, PhD \\ Foundations of Education Department, \\ Faculty of Education, Assiut University, Egypt
}

doi: 10.19044/esj.2016.v12n22p249 URL:http://dx.doi.org/10.19044/esj.2016.v12n22p249

\begin{abstract}
The current study aimed at recognizing the concept and aims of performance evaluation besides to shedding light on balanced Scorecard as it is considered one of the modern models in performance assessment and evaluation. The study aimed at assessing the performance of accredited faculties at Assiut University by using this scorecard. The researcher used the descriptive method as it suits the study nature. The study sample consisted of $20 \%$ percentage of the original society of the study from staff members and with $5 \%$ percentage of the original society of study from students.it was selected in a random way. The current study came down to some important results related to the theoretical framework and the field study:(1)the balance scorecard is considered one of the modern tools and the most effective tool in measuring and assessing the balanced performance because it gathers among the financial and non-financial tools, besides to that, it gathers the quantitative and specific values in addition to the external and internal factors on the short and long term.(2)the performance related to the internal process efficiency came at a medium degree at all the performance was weak, while the performance was medium at the total of the sample size. The researcher ended his study with setting some important recommendations to implement this technique in an effective way.
\end{abstract}

Keywords: Balanced Scorecard, Assessment, Accredited faculties, Performance

\section{Introduction}

The assessment of performance plays an important role at institutions as it shares in decision-making, control innovation and creativity.

Also, it plays a vital role in giving a real picture for higher administrations about what happens at the institution so as to they can solve 
any problems (Erouh, 2011). Tocarry out that, the institution found that there is a new technique inassessment which is called Balance Scored card $>$ This technique is considered one of the most important techniques in assessing performance at the strategic administration. It is characterized by gathering between the high and low measures that are flexible in following and connecting to the organization strategy.

The first formal appearance of the balance scorecard dates back to 1992 in North America by the consultant, Robert Kaplan and the founder consultant of research unit, David Norton. This was done by a study which lasted for a year and was applied at twelve institutions in Canada and the United States of America in order to assess their performance. The two researchers indicated that there should be a balance between the financial and non-financial areas, this balance can be achieved through assessment. This made the chance to find a total performance indicator which gives complete and quick views around the institution activity (Paul Niven, 2002).

Others say that using the balance scorecard to assess performance of educational institutions as they are non profit ones will achieve the total quality requirements (Younis \& Eman, 2010).

The Balanced Scorecard helpsinstitutions to follow not only the financial results, but also leading the competencies growth and obtaining non-materialistic resources as well(Jean\&Jacquee,2008).

The balance Scorecard helps making the educational institutions to assess and increase the efficiency of the accredited colleges at Assiut university in Egypt.As there is a worrying situation in the role of the national authority for quality assurance and accreditation that is represented in gathering between the roles of enforcing quality, granting accreditation and institutions,besides to the programs' accreditation on one hand and its multiplicity with other agencies and its membership is done by governmental appointments on the other hand. (OECD and World Bank, 2010).

The university institutions witness important changes which are imposed by the great competitiveness. As it becomes necessary for these institutions to improve their performance to stay and live in doing their tasks. This depends on the extent of its ability to achieve the setting goals. In order to know the extent to which they achieve their goals, these institutions need to assess what was planned at the beginning of the strategy. This can be done through the dependence on the tools that help them to assess, especially at the accredited colleges.

Although there is an urgent need for university institutions to assess and measure performance of governmental universities in particular, the assessment is still extremely difficult because these institutions are less flexible according to the culture of change. Furthermore, theu turn to meet the society needs and improving its welfare. These institutions have rare 
resources and they do not seek to maximize profits to select the goal of achieving profit for them (Ogawa \& Tanahashi, 2008).Thus, the government universities in general and the accredited colleges in particular at these universities need the development of performance assessment techniques using the modern techniques in the assessment process.

The used technique of assessment, is considered one of the successive factors for the colleges to last and achieve innovation, development and continuous improvement so that they can reach high efficiency rates by which the aspects of good performance are defined and the planned aims are achieved (Purbey et al,2007).

In order to improve the system of measuring and assessing university performance so that it can reach a system of measurement which gathers all the aspects related to the institution surrounding and activity, the balance scorecard model (BSC) was used to achieve that. This model, recommended by Kaplan and Norton, was discussed for the first time at the university of Harvard in 1992 (Erouh, 2011).

Many studies referred to the importance of using the balance scorecard in assessing institutions in general, and university institutions in particular. The study of (Nasreen S.,2012) indicated that institutions need a mechanism to apply strategies, and evaluating performance. This can be fulfilled by using the Balance Scorecard. The study of (Raghda M.\& Leith S.,2013) asserted institutions must depend on a developed tool to measure the performance of information systems ,i.e, ,the balance scorecard as an alternative to the traditional methods in measuring performance. The study of Ahmed et al.,2014) stated that among the most prominent administrative models which appeared at the field of university and higher education, is the Balance Scorecard which manages and evaluates institutions.

The study of (bayoumy El-Tahway \&Reda El-Melegy,2011) asserted that colleges need to assess their performance through a tool which focuses on some non-financial aspects such as organizational learning and its community role. These aspects are represented in the dimensions of the balance scorecard. The study of (Alaa A.\&Mayson,2011) recommended that university administrations should held training courses that show the importance of implementingbalance scorecard and the mechanisms of carrying out it. Wheras the study of (Samasem K.,2013) showed that the balance scorecard can be implemented at governmental universities and it can increase the effectiveness of university and improve its performance.

Therefore, the problem of research revovles around the the use of balance scorecard at Assiut University (Accredited Colleges as a sample). As Balance Scorecard is considered one of the recent trends in assessment, These accredited colleges are eight. Accordingly, there are colleges of Education and Arts which are accredited at Assiut university, and at all over 
the country. The college of medicine is among the eleven accredited colleges in Egypt. The college of science is among the eight accredited colleges in Egypt.The colleges of Pharmacy and Engineering are among the seven accredited colleges in Egypt. The college of Veterinary is among the five accredited colleges in Egypt. The college of Agriculture is among the four accredited colleges in Egypt (National Authority for Quality Assurance and Accreditation,2015). The choice of the accredited colleges depends on the need of accreditation and quality lasting.

The problem of research comes from the researcher's view that public universities and accredited colleges need to develop the performance assessment techniques by using the modern techniques in assessment. Hence, the research problem is represented in the way by which accredited colleges at Assiut University are assessed by the balance scorecard". The objects of the study are as follows:

The principle aims of the study were represented in the following objects as follows:

- $\quad$ recognizing the assessment performance definition and its aims.

- $\quad$ identifying the balance scorecard dimensions.

- $\quad$ studying the performance assessment of accredited colleges at Assiut university.

\section{The importance of study}

The study importance was represented in the following points:

- $\quad$ The balance scorecard can be used to assess the institution and its implementation of the measurement dimensions instead of one dimension ,especially it became necessary for institutions to depend on measurement indicators whether financial or non-financial.

- $\quad$ The sample nature as the accredited colleges are on their way to fulfill the continuous improvement, hence it is necessary to use overall measurement techniques.

- $\quad$ The study findings may be theoretical and practical reference for Egyptian university education in general and for Assiut University and its colleges in particular.

\section{The study Questions}

The study questions were represented in the following ones:

- What is the definition of the performance assessment and its aims?

- What is the definition of the balance scorecard and its dimensions?

- What is the reality of accredited colleges' performance at Assiut University? 
For this reasons, the research was to study the assessment of performance at accredited colleges by using the balance scorecard technique.

At the present study, the researcher presents the definition and aims of performance assessment besides to the dimensions of the balance scorecard technique. There are some findings and recommendations of the field study which are consistent with the benefits of using the balance scorecard technique in measuring and assessing performance at educational institutions.

\section{Conceptual framework:}

\section{performance assessment defined:}

Performance measurement is the continuous control of achievements of the organization programs and registering the progress toward fulfilling thepreviously set aims (Taher \&Wael, 2007).

University performance assessment is a way to study the university ability to achieve its goals and to achieve what is required from it in a specific period. It is not an independent process, but it is a stage among the educational stages in organizing the university represented in the specific dimensions in university evaluation from stability, response, psychological field, quality assurance, accreditation and materialism (Mohamed W., 2006).

The researcher defines procedurally the university performance measurement as "the ability of university system to control, in a continuous way, the ability of the college to perform its role efficiently and effectively, with productivity and quality in the suitable time and at high proportion.

\section{performance assessment objects}

It is necessary for organizations to measure its work results even if they did not get from these results an reward or a return. The information which is gotten hinders the organization to do the best. As the organization disability to measure the performance results in the in ability to measure control it, thus it can not be managed. Thus, the organization needs measuring its performance for the following reasons (AbdEl-Raheem, 2008):

- $\quad$ Control: measuring performance helps in reducing the deviations which happen during work.

- Self-assessment: measurement is used to assess the process performance and to define the required improvements.

- $\quad$ Continuous improvement: measurement is used to define the faults resources, process attitudes, mistakes prevention and defining the efficiency and effectiveness of process besides to improvement chances.

- Administration assessment: without measurement, there is not a method by which organization makes sure that it achieves the adding value of its aims and it works efficiently and effectively. 


\section{Balance scorecard defined:}

The balance scorecard is a concept in its name, but it is not a recent concept in its evolution. It appeared as a result of developing a number of concepts and theories such as activity based administration, management by goals, the total quality, management, and strategic management, behavioral theory in economics, authority negotiation and decentralization in decision making. What distinguish the balance scorecard from these concepts is that, it presents and gathers all these concepts and theories together to show the best things and merits of these theories and concepts is one model to measure performance in a complete way to cover all organizations areas (Nasreen, 2013).

Balanced scorecard is defined by (Robert K. \& David N.,1992) as “a system which presents a coherent set of ideas, principles and a road map for companies to follow and track the vision translation in a related set of performance measures which contribute in achieving tasks and setting tasks and works strategy besides to linking the strategy with the works, and coordination between individual performance and organizational performance to achieve the organization aims by using the modern techniques.

The researcher defines balance scorecard as "a technique of the modern techniques in assessment, which does not only include the financial dimension, but it includes the beneficiaries' dimension, internal process dimension, development, learning and growth dimension and social performance dimension”.

\section{The balance scorecard dimensions}

The general framework of balance scorecard includes five dimensions which work together through interdependent relations among one another to achieve the institution strategy in terms of tasks and defined goals. The dimensions of the balance scorecard can be clarified in the following figure:

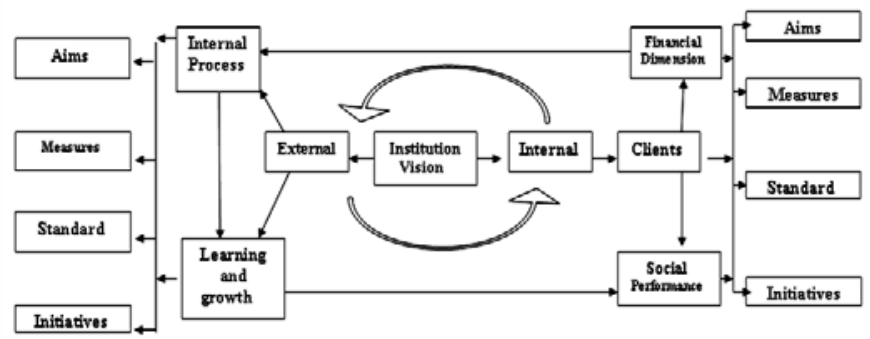

Figure 1-4.: the balance scorecard dimensions 
It is clear from the previous figure that balance scorecard dimensions are strongly correlative strongly related to the institution vision and its internal and external aspects. It is clear that each dimension measures the following points: aims, whether these aims express the desired results which fulfill the institution vision, measures which define the aim status which should be fulfilled through comparing it to a previously defined value, standards means the estimation upon which deviations estimation is measured, and initiatives which means the projects and procedures which are done by the institution to achieve their aim. These dimensions are represented as follows:

\section{The financial dimension}

The financial dimension is considered one of the most important dimensions of measuring and assessing performance. It represents measures defined toward achieving the goals and standing on the return level, especially the financial return achieved for institution strategy and which focus on; the size and level of operational institutional income, return ion the capital that resulted in cost's reduction, growing of benefit degree from the new and current products, return on the owners' rights and return on the total of assets (Taher \& Wael, 2008).

The financial techniques can be used through their correlation with any general strategy whether at growth stages settlement stages or the stages of maturity (Robert R.\& David N.,1996).

Thus, it requires achievement of the financial growth, profitability and reducing the risk from the perspective of the surroundings related the institution which are as; staff members, students, employees, graduates, parents, administration, college and society.

\section{The beneficiaries' dimension:}

Many institutions and organizations have a general mission which focuses on customers (beneficiaries) to gain the first class in achieving the value for their customers.. Accordingly, the institutions performance, from the perspective of its clients, became a priority for the upper management. The clients' interests can be classified into four categories: time, specification, performance and service. The specification measures are the measurements of demerits levels at the introduced products as the client realizes and measures. IT also measures the delivery at the suitable time. According to the service and performance measures, they measure the way by which the organization services and products contribute to find a value for their customers (Alaa \& Mayson, 2011). Consequently, the clients must find a value of joining this faculty except others, whether they were customers inside the institution (students) or external ones (society and parents). 


\section{The internal activities and processes dimensions:}

The internal activities and processes are divided into a chain of activities and the internal stages of institutions which offer value for clients at the university institution. It includes three cycles: First, the cycle of research and development which defines the market area size which will absorb the product, the service and customers' type. Second, the cycle of performance in which the required design of the product or the educational service is defined. Third, the cycle of post production service in which the activities focus on defining the nature and type of the introduced services for clients, the period of presenting the services is included at this cycle besides to learning and training programs prepared by the institution to train the clients on how to use the products introduced to them (Mohamed A., 2009).

The processes aim at making the institution reach the defined quantity in less time and cost besides to achieving the quality and typology. Also, they give interest to fixing the available resources as it defines the benefit level from the available absorbing energy. Additionally, they define the level of usage of the available resources in comparison to the setting goals. This is done in terms of what the institution possess from ability to compete in the market(Maher M.\& Marwan M.,2009).

Thus, the internal process dimension means that operational procedures definethe pioneering stages through defining goals, its priorities and the way by which it can achieve goals in a maximum time and with less cost in order to satisfy the clients (students), the faculty members and stakeholders.

\section{Learning and growth dimension}

Learning and growth dimension is the fourth dimension at the balance scorecard, which expresses the bases that the organization should adopt to create growth and the required improvements so that it can achieve the goals at long-term. In case the organization can not invest in human resources to be qualified scientifically and practically in a great way, besides to developing the information production techniques and change the routine procedures of the organizational structure, it will not be able to achieve the strategic aims of customers and internal process dimensions. Thus, it might not be able achieve the financial aims. This dimension evaluates the organization performance through improving the employees' abilities by the measures such as employees' stratification, keeping on employees and employees' productivity (Alaa A \& Mayson A., 2011).

Thus, it covers growth, learning and evaluation, the offer of support climate for change, institutional growth and innovative evaluation. It focuses 
on the institution ability to modernize and develop employees' abilities within institution.

\section{Social performance}

Great interest was given to the social performance and interest, especially at the last time or period in many ways whether locally or globally. This was represented in the conference of environment and development in Brazil in 1992 which aims at the necessity of discipline of business organization to apply the environment protection and development. There is a responsibility upon these organizations as they can harm environment with loses because of their activities whether these harms were visible or not (Narmeen, 2002).

Others say that the institution responsibility is defined at the first degree by its social performance and what it is presented from benefits to society, and this is the first criteria to its development and continuity at its environment (Hares K., 2005).

Thus, the social performance includes the link between institution, society and the services introduced by the college to environment and society and its ability to face the social problems and contribution to solve them effectively.

\section{The field study framework}

The study tool was prepared by the author. This tool is related to the balance scorecard. The questionnaire was used and calculated by using (11) peer review. The questionnaire stability was calculated by using the retest method and the value stability was (0.83).

Some statistical techniques were used such as: the proportional weight, the medium for the proportional weight of sentences to get the proportional weight of each dimension and calculating confidence limits of the samples to recognize the extent of achieving the proportional weights.

\section{The field study results}

After the applying the balance scorecard upon the sample of staff members, the study results are represented in the following table as follows;

Table 3.1.1.: the proportional weight for a sample of staff members and students:

\begin{tabular}{|c|c|c|c|c|c|c|c|c|c|c|c|}
\hline \multirow[t]{2}{*}{ College } & \multirow{2}{*}{\multicolumn{2}{|c|}{$\begin{array}{c}\begin{array}{c}\text { Financial } \\
\text { Performanc } \\
\text { e }\end{array} \\
\text { (S.M.) } \\
\text { sample }\end{array}$}} & \multicolumn{3}{|c|}{$\begin{array}{l}\text { Customers and } \\
\text { beneficiaries }\end{array}$} & \multicolumn{2}{|c|}{$\begin{array}{l}\text { Internal } \\
\text { process }\end{array}$} & \multicolumn{2}{|c|}{$\begin{array}{l}\text { Learnin } \\
\text { g of } \\
\text { growth }\end{array}$} & \multicolumn{2}{|c|}{$\begin{array}{c}\text { Social } \\
\text { performanc } \\
\mathrm{e}\end{array}$} \\
\hline & & & $\begin{array}{l}\text { (S.N } \\
\text { sam }\end{array}$ & & $\begin{array}{c}\text { (S)sampl } \\
\mathrm{e}\end{array}$ & $\begin{array}{l}\text { (S.N } \\
\text { sam! }\end{array}$ & & $\begin{array}{l}\text { (S. } \\
\text { san }\end{array}$ & & & \\
\hline & $\mathrm{P}$ & $\mathrm{O}$ & $\mathrm{P}$ & $\mathrm{O}$ & $p$ & $\mathrm{P}$ & $\mathrm{O}$ & $\mathrm{P}$ & $\mathrm{O}$ & $\mathrm{P}$ & $\mathrm{O}$ \\
\hline College of & 0.64 & 1 & 0.62 & 3 & 0.58 & 0.61 & 4 & .59 & 5 & 0.6 & 2 \\
\hline
\end{tabular}




\begin{tabular}{|c|c|c|c|c|c|c|c|c|c|c|c|}
\hline science & & & & & & & & & & & \\
\hline $\begin{array}{c}\text { College of } \\
\text { Engineerin } \\
\text { g }\end{array}$ & 0.637 & 3 & 0.64 & 2 & 0.71 & 0.65 & 1 & 0.61 & 4 & 0.64 & 2 \\
\hline $\begin{array}{c}\text { College of } \\
\text { Agriculture }\end{array}$ & 0.66 & 1 & 0.61 & 4 & 0.54 & 0.62 & 3 & 0.57 & 5 & 0.64 & 2 \\
\hline $\begin{array}{c}\text { College of } \\
\text { Medicine }\end{array}$ & 0.63 & 4 & 0.67 & 2 & 0.60 & 0.67 & 2 & 0.64 & 3 & 0.69 & 1 \\
\hline $\begin{array}{c}\text { College of } \\
\text { Pharmacy }\end{array}$ & 0.57 & 3 & 0.59 & 2 & 0.599 & 0.56 & 4 & 0.6 & 1 & 0.57 & 3 \\
\hline $\begin{array}{c}\text { College of } \\
\text { Veterinary }\end{array}$ & 0.55 & 4 & 0.5 & 5 & 0.56 & 0.6 & 2 & 0.67 & 1 & 0.57 & 3 \\
\hline $\begin{array}{c}\text { College of } \\
\text { Education }\end{array}$ & 0.58 & 3 & 0.52 & 4 & 0.698 & 0.59 & 2 & 0.62 & 1 & 0.38 & 5 \\
\hline $\begin{array}{c}\text { College of } \\
\text { Arts }\end{array}$ & 0.65 & 1 & 0.57 & 3 & 0.636 & 0.53 & 4 & 0.41 & 5 & 0.64 & 2 \\
\hline Total & 0.623 & 4 & 0.62 & 3 & 0.645 & 0.63 & 2 & 0.60 & 5 & 0.66 & 1 \\
\hline
\end{tabular}

(P) Means proportional weight, (O) means order,(S.M.) means staff members, (S.) means students

\section{The financial dimension findings:}

It is clear from the previous table (3.1) that financial performance dimension at the balance scorecard is fulfilled to a quite degree for all the accredited colleges at Assiut university. Accordingly colleges of science, Agriculture and Arts came at the first class in this dimension. The colleges of Engineering, Pharmacy and Education came at the third class in fulfilling this dimension, while the colleges of Medicine and Veterinary came at the fourth class in fulfilling this dimension. The financial performance was unachieved for all sample size at the fourth order. This dates back to the economic conditions reflection on suspension degree on education; especially others look at education as a consuming institution. These findings agree to the study of(Samasem K.,2013) in which the financial dimension indicators showed a negative change such as education programs which are funded as a proportion to the total of the required funding.

\section{Beneficiaries' dimension findings:}

It is clear from the previous table that beneficiaries' dimension which is related to staff members, is fulfilled to a quite degree, as the college of Science came at the third order, besides to the college of Arts. While it was achieved at the second order for the colleges of Medicine, Engineering and Pharmacy. It came at fourth order for the colleges of Agriculture and Education. On the other hand, this dimension came at a lower level and it was not fulfilled for the college of Veterinary which came at the fifth order. 
The beneficiaries' performance was unachieved for all sample size at the third order.

For the beneficiary students' sample, the dimension was fulfilled to a quite degree at the colleges of science, Engineering, Agriculture, Medicine, Veterinary and Education. The dimension was not achieved at the colleges of Pharmacy and Arts. This dimension was unachieved for all sample size. This indicates that colleges in its progress phase to satisfy students' needs and achieve their desires and satisfaction, did not reach the desired level .This dates back to curriculum and educational environment which do not put in consideration the students' needs.

The findings of this dimension agree with the study of (Bayoumy \&Reda, 2011) which asserted that university education suffers from the isolation of curriculum from students' desires and does not care about their expectations and ambitions in addition to the absence of the strategic direction and dimension at the strategic assessment processes for institutional performance. Also, the findings of this dimension agrees with the study of (Ahmed et al.,2014) which indicated that there are problems related to the decreased interest for modernizing the university role in setting strategies, plans and programs that attract students.

These findings were coherent to a great degree with the societal viewpoint of the collegeconcerning the job opportunities in the future- more than that of the actual performance of college. The college of Agriculture was having the same societal viewpoint, but it does not get the same result because the majority of the agriculture students arefrom poor families and their maximum ambition it to join university.

\section{Internal process efficiency dimension findings}

It is clear from the pervious table concerning the sample of staff members that the dimension of internal process efficiency at the balance scorecard is achieved at a quite degree, as the college of Engineering came at the first order in fulfilling this dimension. While the colleges of Medicine, Veterinary, Education came at the second order in fulfilling this dimension, it was achieved to a quite degree at the college of agriculture, and the colleges of science and pharmacy came at the fourth order in achieving this dimension, the college of arts came at the fourth order, but it did not achieve this dimension .It is clear that college of Arts, although it was accredited, do not have the efficiency of the internal processes to a required level, this dates back to the diversity of departments at college of arts in comparison to other colleges besides to the absence of integrity among these departments and college administration.

These findings agree with the study of (Alaa\&Mayson,2011) which indicated that although colleges attempts to give interest to Administrative 
work which enhance the view that support the internal processes, but they are not influencing at the field, in addition to that, the majority of internal processes are characterized by individual efforts of staff members and there is not a plan set by the administration.

\section{Learning and growth dimension findings}

It is clear form the previous table concerning staff members that this dimension was fulfilled to a quite degree, as the college of Pharmacy, Veterinary and Education came at the first order in achieving this dimension. The college of medicine came at the third order in achieving this dimension. While the college of engineering came at the fourth class and the colleges of science and agriculture came at the fifth and they achieved this dimension to a quite degree, but the college of Arts came at the fifth order and did not achieve this dimension besides to the total size of the sample.

This dates back to the modern growth and development of the college, as the long period is enough to establish a system capable of making change, innovation and growth inside the institution. Thus, the decreased level of performance of the college of arts is due to being the last college in growth to be studied. These findings agree with the studies of (Alaa\&Mayson,2011),(Samsem,2013)and(Ahmed,2014) which indicated that the dimension related to learning and growth does not reach the required level.

\section{The social performance dimension findings}

It is shown form the table (3.1) concerning staff members that the social performance dimension is fulfilled at a quite degree, as the college of Medicine with the total of the sample size, came at the first order to achieve this dimension. The findings of the college of medicine came as a result of the social performance of the college, this is due to its social relations and its services to society represented in its university hospital not in Assiut, but for Upper Egypt as well. The colleges of Science, Engineering, Agriculture and Arts came at the second order, while the colleges of Pharmacy and Veterinary came at the third order in achieving this dimension. On the other hand, at the college of Education this dimension was not fulfilled although there are many centers of society service such as the public service center and adult learning center, this also dates back to the lack of interest to employees and scientific researches.

These findings agree with the study of (Bayoumy \&Reda, 2011) which indicated that there is a weakness in the relation of curriculum content at colleges to society needs and the weak correlation of scientific research at college to the societal development issues. 


\section{Conclusion}

The study in its theoretical and field frameworks came down to some important findings and recommendations. These findings and recommendations are generated from both the theoretical and field aspects.

\section{General findings of the study:}

The study represented in theoretical framework and field aspect came down to some findings, most important of which are as follows:

The balance scorecard is considered one of the modern tools and the most effective tool in measuring and assessing the balanced performance because it gathers among the financial and non financial tools, besides to that, it gathers the quantitative and specific values in addition to the external and internal factors on the short and long terms.

The dependence on the traditional tools to measure and assess the accredited colleges is not enough to get a complete view about the aspects and dealings related to the institution and its environmentThis shows lack and the non existence of overall view in offering correct information about the institution process so that it can build decisions upon these processes in an effective way, hence it will be a successful one.

The assessment of the performance related to the accredited faculties is considered one of the important and vital processes in order to direct performance and developing it, which will result in achieving the institution goals and strategy success.

Although the colleges which are the subject of study were accredited, the performance did not reach the medium level of performance. Thus, they to reconstruct the administrative and financial hierarchies so that Assiut University can compete the global universities.

The financial performance came at the medium degree at all the accredited colleges, while it was weak at the total sample size. These colleges were seeking to increase the budget related to education technology at a great degreesuch asthe colleges of science and Engineering.

The performance related to the beneficiaries or students came at a medium degree at all the accredited colleges except the college of Veterinary for staff members' sample which their performance was weak. Also, the total of sample size was weak. The dimension came at a medium degree at all the accredited colleges except the colleges of Pharmacy and Arts for the sample of students or the customers, was weak, while the performance was weak for the total sample size.

The performance related to the internal process efficiency came at a medium degree at all the performance was weak, while the performance was medium at the total of the sample size. 
The performance related to learning and growth came to a medium degree at all the accredited colleges except the college of Arts, and the total of sample size in which the performance was weak.

The social performance came at a medium degree at all the accredited colleges except the college of Education in which the performance was weak, and the performance was moderate at the total size of the sample.

\section{Recommendations:}

It is necessary for the accredited colleges to adapt with the international and external environment; this comes with giving considerations to the latest things which are related to the institution in order to keep on accreditation.

The National Authority for Quality Assurance and Accreditation (NAQAA) should reviewthe different techniques of evaluation of the educational institutions through which the university institutions can depend on it.

The higher and upper management whether university president, college dean or heads of departments) should believe in the necessity of the use of the modern techniques and their importance in evaluation in general and the addition to obtaining the help of experts in applying this card at the accredited colleges.

The university administration and the different colleges should review their administrative techniques, as well as, the financing techniques in order to stand in a correct position and transform the points of weakness into better ones.

For accreditation continuity, all employees and staff members should participate at setting plans and budgets, in addition to limiting performance measures with a system of rewards and motivations.

The continuous development of control techniques should be done in order that the institution can improve its performance in continuous and effective ways.

The accredited university colleges should show the social role through giving interest to all elements of its surrounding whether internal and external, this can be done by the ideal exploitation of human capital, giving interest to the social aspect and the surrounding environment, participation at decisions because these factors contribute in improving the university position at society through its developmental and service contributions.

Giving interest to the human element inside the institution as well as creating work opportunities which can contribute in satisfying individuals' needs and creating a suitable work climate which encourages them to achieve good performance level. 
The participation of all employees and beneficiaries of the college in facilitating the institution's matters, defining its goals, opening the field of suggestions and decision-making in addition to innovation at the different levels.

The university institutions should cope up with the progress and development that happen in recent assessment, especially at the field of facilitating the control of running through the application of the balance scorecard which is considered a measure that is characterized by its converge, generalities, balance and mufti dimensions whether internal or external; financial or non financial; quantitative or qualitative, short-term or long-term and the social and environmental performance.

The upper administration, should establish a system of rewards and motivations, which allows for employees to be promoted and can help them to improve theirperformance.

The necessity of benefitting from the different experiences and competencies that have the capacity to contribute effectively within the organization. This is done with the exception of not looking at its close relation or its far relation with the upper a management (the upper authority).

\section{References:}

Abdel-Raheem M. (2008). Measuring performance: Growth, historical development and importance: The modern techniques in assessing governmental performance, Arabian organization for Administrative development Cairo.p.498.

Ahmed et al. (2014). Evaluation of Egyptian universities performance using balance scorecard, Journal of college of education in Banha,(99).Egypt.pp.161-186.

Alaa A. \& Mayson A. (2011). Measuring El-Maousel university performance and its Assessment by Balance Scorecard; Journal of economic sciences, 7, (28).pp.159-199.

Bayoumy \& Reda .(2011). The Assessment of the Colleges of Education in Egypt by using the Balance Scorecard, Journal of college of education, Ismailia, Egypt.(21).pp.5,91.

Erouh M. (2011). Role of balance scorecard in measuring and assessing continuous development at medium institutions for food manufactures: A comparative study between El-Hadana Malbah in El-Masila and El-Taal Malbah in Steaf, Algeria: Farahat Abbas university.

Hares K.E. (2005). The role of accountability information in measuring and assessing the social performance for industrial institutions, a paper presented to the fourth scientific conference for progress and Innovation, college of financial and administrative science, Jordan.pp.265-286. 
Jean Brilman, Jacquee Heracd. (2008). les meilleurs pratiques de management, 6eme edition, edition d' Organization, Paris.p.210.

Maher M.\& Marwan M.(2009). The impact of applying the balance scorecard(BSC) in enhancing the financial and strategic performance for the Palestine national banks in Ghaza sector, field study,Journal of Islamic university, Ghaza (human studies series),17(2).Palstine.pp.741-788.

Mohamed A.(2009). Evaluation of Limited Palestinian bank performance by using the balance scorecard, Master Thesis, Islamic University: college of education :Ghaza.pp.44-45.

Mohamed W. (2006).A vision to develop the university and to set standards for performance evaluation, the 13th Annual National conference: Arab universities in the 21st century: present and visions. Cairo: Ain-Shams university. Egypt.pp.175-199.

Narmeen A. (2000).A suggested approach to environmental review as a tool of environmental performance assessment for corporations, Egypt, Port Said: Suez Canal university. PHD Thesis.pp.1-5.

Nasreen S.(2012). Evaluation the strategic performance of Egyptian universities using balance scorecard. Journal of Arabian education future. 19 (81).pp.11-165.

National Authority for Quality Assurance and Accreditation (NAQAA) (2015). Toward a specific transformation in Higher education, a paper presented at the conference and festival of higher education sector of the authority. Cairo.p.24.

Ogawa,H. and Tanahashi,K. (2008).Effect of New Public Management: Data Environment Analysis: Government Auditing Review.15.pp.47-49.

Organization of economic development and cooperation (OECD) \& World Bank (2010).Review of National polices: Higher education in Egypt. Egypt.p.219.

Paul Niven.(2002).Balanced scorecard :step by step,Wily:Canada.p.29.

Purbey,s. et al.(2007). Performance Measurement System for Healthcare Processes", International Journal of Productivity and Performance Management, 56 (3).pp.241-251.

Raghda M. \&Leith S.(2013). The Assessment of Information Systems Performance using the balance scorecard: a developmental suggestion, ElRafedeen Development,35(113).pp.73-90.

Robert K.\& David N.(1992). The balanced scorecard, measures that drive performance", Harvard business review, Jan-Feb.p.71.

Robert K..\& David N. (1996). Linking the Balanced Scorecard to Strategy", California Management Review, 39, Paul Niven (2002). Balanced scorecard step by step, Wily, Canda.p.57.

Samasem K.(2013).The Effectiveness Extent of using the Balance Scorecard in Improving the Public Universities: A field study on the college of 
commerce, Ain Shams University, Egypt. Journal of Economy and Commerce (2).1151, 1228.

Taher M. \& Wael S. (2007).The Strategic Management: An Integrated Methodological Perspective. Jordan: Wael Home Publishing.p.487.

Taher M. \& Wael S. (2008).Studies in strategy and balance scorecard. Jordan: Zahran home publishing.p.226.

Younis H.\& Eman G.(2010). The Systems of Evaluating the Egyptian Public Universities while Applying the Total Quality Management, college of commerce and business administration in Helwan university: Journal of Commercial Research and Studies, Part (1).(2).Egypt. 